\section{The effects of advance information on human information processing in a choice reaction task}

\author{
ROBERT J. REMINGTON \\ IBM Corporation, Research Triangle Park, N.C. 27709
}

A study was conducted to explore the human's ability to take advantage of the advance information which significantly reduces the amount of uncertainty associated with the up-coming trial in a choice reaction task. Each of eight Ss performed under three experimental conditions: (1) a six-choice condition with 2.58 bits of average stimulus uncertainty, (2) a four-choice condition with only 0.99 bits of average stimulus uncertainty, and (3) a condition consisting of a randomized merge of the stimulus sequences used in the previous two conditions in which information regarding the uncertainty (i.e., 2.58 or 0.99 bits) associated with the up-coming trial was advanced $.5,1$, or $2 \mathrm{sec}$ before the presentation of the stimulus signal. It was found that the Ss could reliably take advantage of advance information to reduce their response time as long as the delay between the advance information and the stimulus signal was 1 sec or longer. In addition, it was found that advance information had little effect on first- and second-order sequential effects customarily found in choice reaction time data.

In many man-machine systems, the human is required to monitor and process information from a machine-generated display and make the appropriate response from a finite repertoire of responses. The incorporation of a computer into a man-machine system, with its ability to process information and up-date system status at incredible speeds, introduces some interesting possibilities for facilitating manmachine information transmission performance. For example, in the case w h e e a $n$ a c u rate response on the part of the human is very critical, the computer could be used to present alerting information to the human in such a way as to reduce significantly the amount of uncertainty associated with the up-coming critical condition and thereby theoretically reduce, on the average, the human response time. In its simplest form, the situation described above can be viewed as a discrete choice reaction condition with partial advance of information. Recent psychological research on human information processing has produced a substantial body of theoretical and empirical knowledge from which the gains in response speed and accuracy achieved by various reductions in stimulus and/or response uncertainty can be predicted (e.g., Hick, 1952; Hyman, 1953; Alluisi et al, 1964; Hyman \& Umiltá, 1968). However, a search of the information processing literature revealed only two studies of human information processing behavior under a discrete choice reaction condition involving partial advance of information. Leonard (1958) investigated the effect of advance information by comparing reaction time (RT) under three conditions: a six-choice task, a three-choice task, and a set of experimental conditions in which a two-choice task preceded two three-choice tasks by various durations. It was found that as the separation between the two and three-choice tasks was varied from $0.04 \mathrm{sec}$ to $0.50 \mathrm{sec}$, performance became increasingly similar to, and finally identical with, that under the control three-choice condition. Partial advance of information by $.30 \mathrm{sec}$ enabled the $S$ to respond to the three-choice signal preceded by the two-choice signal as efficiently as a pure three-choice situation. The small sample size (i.e., one $S$, the $E$ himself) and the experimental condition which required $S$ to make two responses (i.e., a response to the advance information as well as a response to the final information), thereby bringing the psychological refractory period phenomenon into play, reduced the amount of information which could be derived from this study regarding the effect of advance information under the condition of interest. Beller (1971) presented in advance one of a pair of letters to be matched. The advance information shortened $R T$ under a variety of matching tasks. However, the author did not report the interval between the advance information and the stimulus signal.

The experiment reported in the present paper was conducted to explore the effect of advance information on human information processing in a discrete choice reaction situation. More specifically, it represents an initial attempt to determine the human's ability to take advantage of the partial advance of information in order to respond more efficiently. Secondly, the experiment was conducted to determine the effect of advance information upon sequential effects in choice RT previously reported by the present author as well as other researchers. SUBJECTS

Eight volunteer Ss participated in the experiment. The Ss, skilled female typists participating in on-going human factors research at IBM, ranged in age from 19 to 38 years.

\section{APPARATUS}

The signals were presented by means of a visual display consisting of six lights approximately $1 \mathrm{in}$, in diam and two red warning lights located directly above the stimulus lights. Selection of the desired stimulus light, warning light, and the delay between the onset of a warning light and a stimulus light (i.e., the foreperiod) was achieved by means of a prepunched paper tape program. The response device was a small keyboard consisting of six typewriter keys. The keys were numbered, starting on the left, from one to six, corresponding spatially with the numbered stimulus lights. The depression of a key following a stimulus light was followed by the automatic recording of the RT with millisecond accuracy, stimulus number, a code for the foreperiod delay, and the specific key(s) depressed by $S$. Knowledge of a correct response was provided by the lighting of a small green light located above the warning lights on the visual display. The control and recording equipment, located in a room adjacent to the room containing the visual display, allowed for automatic data collection without the necessity of intervening operations by $\mathrm{E}$.

\section{STIMULUS SEQUENCES}

Construction and randomization of the stimulus events for the various stimulus sequences were achieved by means of a computer program. The structural characteristics of the stimulus sequences are presented in the following description of the experimental conditions:

\section{Condition I}

Under this condition, each of six stimulus alternatives were presented equally often. Under all experimental conditions, the foreperiod varied randomly between the three values of $.5,1$, and 2 sec. Condition I, which employed a 192-trial stimulus sequence, contained an average stimulus uncertainty of 2.58 bits. Condition II

The second condition consisted of a 192-trial stimulus sequence in which Signal " 1 " appeared $13 / 16$ of the time, with Signals " 2 ," " 3 ," and " 4 " 
Table 1

Mean RTs associated with each of the three information advaince intervals for various stimulus signal categories and condition components for Condition III

\begin{tabular}{|c|c|c|c|c|}
\hline $\begin{array}{l}\text { Stimulus } \\
\text { signal no. }\end{array}$ & $\begin{array}{l}\text { Condition } \\
\text { component }\end{array}$ & $\begin{array}{l}\text { Inform } \\
.5 \text { sec. }\end{array}$ & $\begin{array}{l}\text { Advance } \\
1 \text { sec. }\end{array}$ & $2 \mathrm{sec}$. \\
\hline 1 & $\begin{array}{l}2.58 \text { Bits } \\
0.99 \text { Bits }\end{array}$ & $\begin{array}{l}380.3 \\
380.0\end{array}$ & $\begin{array}{l}385.4 \\
351.5\end{array}$ & $\begin{array}{l}385.7 \\
349.0\end{array}$ \\
\hline $2,3, \& 4$ combined & $\begin{array}{l}2.58 \text { Bits } \\
0.99 \text { Bits }\end{array}$ & $\begin{array}{l}496.1 \\
498.6\end{array}$ & $\begin{array}{l}497.2 \\
526.8\end{array}$ & $\begin{array}{l}495.2 \\
533.2\end{array}$ \\
\hline $5 \& 6$ combined & 2.58 Bits & 497.3 & 499.0 & 501.2 \\
\hline
\end{tabular}

occurring $1 / 16$ of the time. The four signals employed in this condition were a subset of six signals employed under Condition I, and the average amount of stimulus uncertainty was 0.99 bits.

\section{Condition III}

This experimental condition, the advance information condition consisted of a randomized merge of the two stimulus sequences used in Conditions I and II. Two warning lights were used to provide $S$ with advance information regarding the nature of the up-coming stimulus. The appearance of warning light " $A$ " indicated that the rules governing Condition I (i.e., one of six equally likely alternatives could occur) were in effect for the up-coming stimulus event, while the presentation of warning light " $\mathrm{B}$ " was used to indicate that the rules governing Condition II were in effect. Not taking the advance information into account, Condition III contained an average stimulus uncertainty of 2.17 bits.

\section{PROCEDURE}

Each $S$ performed under all three experimental conditions. All Ss performed under Conditions I and II before Condition III in order to become familiar with the two basic sets of rules incorporated in the advance information condition. However, half of the Ss were presented with Condition I before Condition II, while the other half were presented with Condition II before Condition I. Ss were told the probability associated with the appearance of the possible stimulus events for Conditions I and II in terms of percentages. Under Condition III, $S$ was instructed as to the function of the two warning lights. The Ss were instructed to respond as quickly as possible to the presentation of the stimulus light without making more than $2 \%$ error responses during a given series. for the Ss to respond in terms of the greatly reduced amount of stimulus uncertainty. The difference between the mean RT for Signal "1" for the 2.58-bit component with a $1-\mathrm{sec}$ foreperiod (i.e., $385.4 \mathrm{msec}$ ) and the mean RT Signal " 1 " for the 0.99-bit component with a 1 -sec delay (i.e., $351.5 \mathrm{msec}$ ) was statistically significant $(\mathrm{p}<.01)$. The additional reduction in mean $R T$ associated with the 2 -sec advance of information was not statistically significant.

An analysis of the mean RTs for the low information components (i.e., Signals 2, 3, and 4) for the Condition II subset of Condition III substantiates this basic finding. The mean RT for Signals 2, 3, and 4 combined (see Table 1) for the 0.99-bit component of Condition III was significantly $(p<.01)$ slower than the mean RT for Signals 2, 3, and 4 combined for the high information component for Condition III when $S$ was informed 1 and 2 sec in advance regarding the lower probability of these signals on the up-coming stimulus presentation. Once again, the Ss appeared to be responding as if all stimuli were equally probable when the information regarding the objective probabilities is advanced only .5 sec before the stimulus presentation.

A separate analysis of the error data was judged to be relatively uninformative. The error responses constituted less than $2 \%$ of the total responses. An experiment involving more complex error-producing conditions and more observations will be required to assess the effect of advance information on response accuracy.

Several analyses were performed to evaluate the effect of advance information on sequential effects previously found in choice RT time data. First, the data from all three experimental conditions were examined for the existence of the "repetition effect," i.e., the often-reported finding that the RT to a repeated signal is faster than the $R T$ for a changed signal. Significant repetition effects of similar magnitudes were found for all three conditions. However, a detailed analysis of the repetition effects for individual signals, as introduced by Remington (1970), revealed an unusual finding for the advance information condition. Under Condition III there was no repetition effect for Signal " 1 " for the 2.58-bit component, and the combined repetition effect for the other five signals was slightly greater in magnitude than the repetition effect for the corresponding signals under Condition I. Further experimentation 
will be required to determine whether this is a salient phenomenon associated with advance information or simply an artifact.

A detailed analysis of the RTs for various second-order stimulus patterns produced findings similar to those reported by Remington $(1969,1970$, 1971) and Schvaneveldt \& Chase (1969). Once again, the observed repetition effect was mainly a result of the faster RTs associated with at least two repetitions and the slower $R T s$ associated with stimulus patterns in which a stimulus was immediately preceded by at least two presentations of alternate stimulus events. In general, it appears that the advance information condition had little effect, with the one unexplained exception, on the information-processing processes which produce the higher order sequential effects cutomarily found in choice RT data.

In summary, the findings of the present study indicate that human Ss could reliably take advantage of advance information to reduce their response time in the choice reaction task studied, as long as the delay between the advance information signal and the stimulus signal was about 1 sec. Clearly, further experimentation incorporating a wider range of stimulus uncertainty, complexity in the advance information rules, delays between the advance information and the stimulus information, and practice duration will be required before a useful description of information processing as a function of the various advance information parameters can be formulated. The reported findings also demonstrate the relative stability of previously reported sequential effects under a condition not previously subjected to study.

In addition to demonstrating some empirical aspects of information processing under conditions of advance information, the present study demonstrated the feasibility of a research paradigm which has definite methodological implications for future research in the area of human information processing. As the current theoretical models of human information processing, which postulate successive additive and stochastically independent processing stages, become more and more refined in such a way that they provide predictions regarding the time required by the various stages and the behavioral consequences associated with not allowing enough time to complete a given stage, the advance information paradigm introduced in the present paper may prove useful in verifying these predictions.

\section{REFERENCES}

ALLUTSI E A. STRAIN, G. S., \& THURMOND, J. B. Stimulus-response compatibility and the rate of gain of information. Psychonomic Science, 1964, 1, 111-112.

BELLER, H. K. Priming: Effects of advance information on matching. Journal of Experimental Psychology, 1971, 87, 176-182.

HICK, W. E. On the rate of gain of information. Quarterly Journal of Experimental Psychology, 1952, 4, 11-26.

HYMAN, R. Stimulus information as a determinant of reaction time. Journal of Experimental Psychology, 1953, 45, 188-196.

HYMAN, R., \& UMILTÁ, C. The information hypothesis and non-repetitions. In W. G. Koster (Ed.). Attention and performance II. Amsterdam: North-Holland, 1969 Pp. 37-53.

LEONARD, J. A. Partial advance information in a choice reaction task. Journal of General Psychology, 1958, 49, 89-96.

REMINGTON, R. J. Analysis of sequential effects in choice reaction times. Journal of Experimental Psychology, 1969, 82, 250-257.

REMINGTON, $R$. J. The repetition effect: A methodological consideration. Psychonomic Science, 1970, 20, 221-222. REMINGTON, R. J. Analysis of sequential effects for a four-choice reaction time experiment. The Journal of Psychology, $1971,77,17-27$.

SCHVANEVELDT, R. W., \& CHASE, W. G. Sequential effects in choice reaction times. Journal of Experimental Psychology, 1969, 80, 1-8.

\section{CURRENT LITERATURE ON INFORMATION PROCESSING}

BELLER, H. K. (State University of New York, College at Brockport, N.Y. 14420). Priming: Effects of advance information on matching. Journal of Experimental Psychology, 1971, 87, 176-182.

BERNSTEIN, I. H. (University of Texas at Arlington, Arlington, Tex. 76010), \& EDELSTEIN, B. A. Effects of some variations in auditory input upon visual choice reaction time. Journal of Experimental Psychology, 1971, 87, 241-247.

EKSTRAND, B. R. (University of Colorado, Boulder, Colorado 80302 ), SULLIVAN, M. J., PARKER, D. F., \& WEST, J. N. Spontaneous recovery and sleep. Journal of Experimental Psychology, 1971, 88, 142-144.

EPSTEIN, S. (University of Massachusetts, Amherst, Mass. 01003), \& BAHM, R. Verbal hypothesis formulation during classical conditioning of the GSR. Journal of Experimental Psychology, 1971, 87, 187-197.

EYSENCK, H. J. (Institute of Psychiatry, University of London, London W.C. 1, England), \& GRAY, J. E. Reminiscence and the shape of the learning curve as a function of subjects' ability level on the pursuit rotor. British Journal of
Psychology, 1971, 62, 199-215.

FRITH, C. D. (Institute of Psychiatry, University of London, London W.C. 1, England). Strategies in rotary pursuit tracking. British Journal of Psychology, 1971, 62, 187-197.

GREEN, D. M. (University of California at San Diego, La Jolla, Calif. 92037). Fourier analysis of reaction time data. Behavior Research Methods \& Instrumentation, 1971, 3, 121-125. KENNEDY, T. D. (Arizona State University, Tempe, Ariz. 85281). Reinforcement frequency, task characteristics, and interval of awareness assessment as factors in verbal conditioning without awareness. Journal of Experimental Psychology, 1971, 88, 103-112.

LaBERGE, D. (University of Minnesota, Minneapolis, Minn. 55455 ). Effect of type of catch trial upon generalization gradients of reaction time. Journal of Experimental Psychology, 1971, 87, 225-228.

MALTZMAN, I. (University of California, Los Angeles, Calif. 90024), HARRIS, L., INGR AM, E., $\&$ WOLFF, C. A primacy effect in the orienting reflex to stimulus change. Journal of Experimental
Psychology, 1971, 87, 202-206.

MALTZMAN, I. (University of California, Los Angeles, Calif. 90024), SMITH, M. J., KANTOR, W., \& MANDELL, M. P. Effects of stress on habituation of the orienting reflex. Journal of Experimental Psychology, 1971, 87, 207-214.

MILLER, E. (University of Hull, Hull, England). Handedness and the pattern of human ability. British Journal of Psychology, 1971, 62, 111-112.

RUGH, J. D. (University of California at Santa Barbara, Santa Barbara, Calif. 93016). A telemetry system for measuring chewing behavior in humans. Behavior Research Methods \& Instrumentation, 1971, 3, 73-77.

STAGER, P. (York University, Downsview, Toronto, Ontario, Canada), \& MUTER, P. Instructions and information processing in a complex task. Journal of Experimental Psychology, 1971, 87, 291-294.

SWENSSON, R. G. (Bell Telephone Laboratories, Inc., Holmdel, N.J. 07733), \& EDWARDS, W. Response strategies in a two-choice reaction task with a continuous cost for time. Journal of Experimental Psychology, 1971, 88, 67-81. 